
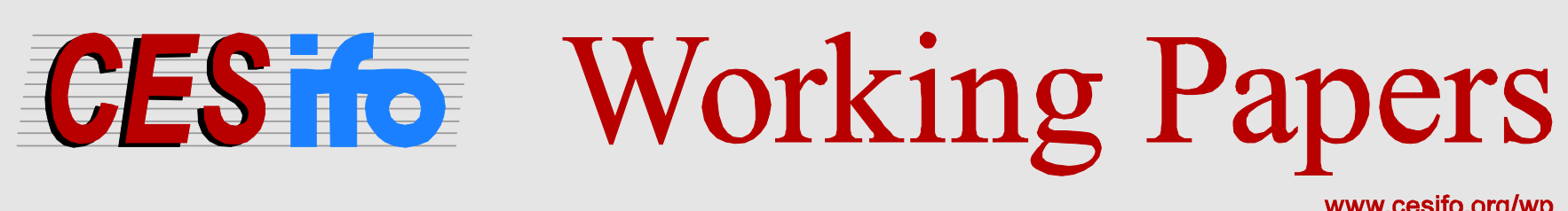

www.cesifo.org/wp

\title{
Sabotage in Contests: An Overview
}

\author{
J. Atsu Amegashie
}

\author{
CESIFO WORKING PAPER No. 4422 \\ CAtegory 2: Public ChOICE \\ OCTOBER 2013
}
An electronic version of the paper may be downloaded
- from the SSRN website:
- from the RePEc website:
- from the CESifo website:
www.SSRN.com
www.RePEc.org
www.CESifo-group.org/wp

\section{CESifo}




\title{
Sabotage in Contests: An Overview
}

\begin{abstract}
This paper reviews the relatively small literature on sabotage in contests. It looks at both the formal game-theoretic literature and the empirical and experimental literatures. The treatment is intended to be intuitive with minimal use of technical jargon.
\end{abstract}

JEL-Code: D710.

Keywords: contests, sabotage, productive effort.

\author{
J. Atsu Amegashie \\ Department of Economics and Finance \\ University of Guelph \\ Guelph / Ontario / Canada N1L 0B6 \\ jamegash@uoguelph.ca
}

January 28, 2013 


\section{Introduction}

Contests are an important and pervasive aspect of economic life. A contest is a game in which players compete over a prize by making irreversible outlays. Election campaigns, rent-seeking games, R\&D races, competition for monopolies, litigation, wars, and sports are all examples of contests. ${ }^{1}$ The fact that the players' outlays are sunk or irreversible is important because it implies that both winners and losers forfeit their bids.

Efforts in a contest can take two forms: (i) effort that directly increases a player's own probability of success or payoff without affecting the capacity of other players to exert effort, and (ii) effort that indirectly increases a player's own probability of success because it reduces the capacity of other players to exert effort. The first type of effort may be referred to as productive effort while the second type of effort may be referred to as sabotage effort or destructive effort. ${ }^{2}$ As Konrad (2000, p. 156) observed,

"Instead of producing information that supports their favored policy outcome, interest groups may use resources to produce negative information on the attractiveness on the attractiveness of particular alternative decisions or try to reduce the effectiveness of a competing interest group's activities. More generally, interest groups may use effort for two different purposes: for promoting their own project or for sabotaging the activities of a specific competing interest group."

The seminal work on sabotage in contests is Lazear (1989). In his model of internal labor tournaments, he referred to sabotage as "industrial politics" and defined it as “... any (costly) actions that one worker takes that adversely affect output of another." Charness et al (2012) describe sabotage as the dark side of competition and following Lazear (1989), Carpenter et al. (2010) refer to sabotage as "office politics."

\footnotetext{
${ }^{1}$ The literature on the contests is large; see, for example, Congleton et al. (2008a, 2008b) and Konrad (2009).

${ }^{2}$ See, for example, Amegashie (2012) and Konrad (2000).
} 
Examples of sabotage are negative campaign ads in political campaigns and dirty and illegal tricks (fouls) in a game of soccer or basketball and time-wasting techniques to make it impossible for one's opponent to exert effort. In internal labor tournaments, contestants may go out of their way to hide valuable effort-enhancing information from each other which is supposed to be shared. For example, based on a survey of Australian manufacturing, Drago and Garvey (1998) found that when the gains from promotion are high, workers are less willing to help their fellow workers. According to Harbring et al. (2007, endnote 1):

"When commenting on the possibility of sabotage at Merck, having introduced forced ranking in 1986, Murphy (1992, endnote 4) refers to John Dvorak, PC Magazine editor, who reports on how a friend attained promotion: This friend cracked the network messaging system which allowed him to read all memos. He sabotaged the workgroup software and manipulated the appointment calendars. According to Dvorak, stealing passwords and destroying important data is an easy task for many employees."

I review some of the main theoretical works in the literature on sabotage in contests and the insights gained from them. I also look at a few experimental and empirical studies of sabotage in contests. The treatment will be intuitive with minimal use of technical jargon. The goal is to make the survey very accessible to readers. Appendix A of the paper briefly presents a technical analysis of contests with sabotage.

\section{Modeling sabotage in contests}

Modeling sabotage can take various forms. It can be modeled as directly reducing the effectiveness of one's opponent's efforts or output which translates into a direct reduction in the opponent's probability of success (e.g., Lazear, 1989; Konrad, 2000; Chen, 2003; Münster, 2007; Gurtler and Munster, 2010, Carpenter et al, 2010) or a direct 
reduction in one's opponent's valuation of the prize (e.g., Amegashie and Runkel, 2007).

It can also be modeled as an increase in one's opponent's unit cost of producing output or effort (e.g., Amegashie, 2012) which then leads to a decrease in (or destruction of) the opponent's output; this increase in one's opponent's unit cost of effort is analytically equivalent to an increase in the opponent's valuation of the prize as modeled in Amegashie and Runkel (2007). ${ }^{3}$

It is important to note that standard rent-seeking effort may itself be wasteful or socially useless and is therefore not different from effort invested in sabotage. This is how rent-seeking effort in contests is viewed in the literature pioneered by Tullock (1967) and extended by Krueger (1974) and several others. ${ }^{4}$ Other than Konrad (2000) who is ambivalent about whether a player's non-sabotage effort is productive or socially valuable, all other models of sabotage in a contest assume that one type of effort is productive or socially valuable while the other effort is destructive (sabotage). ${ }^{5}$ This may stem from the fact that almost all models of sabotage in contests use the labor tournament model pioneered by Lazear and Rosen (1981). This model assumes that employees compete by producing valuable output. Therefore, in his seminal paper on sabotage in contests, Lazear (1989) interpreted sabotage as the destruction of productive effort or valuable output. On page 562, he observed that:

\footnotetext{
${ }^{3}$ Making it difficult for an opponent to exert effort is clearly evident in the above quote by Harbring et al. (2007) where an employee "... sabotaged the workgroup software and manipulated the appointment calendars" of his co-workers. "Stealing passwords and destroying important data" and examples mentioned above illustrate this point.

${ }^{4}$ However, Austin-Smith and Wright (1992), Lohmann (1995), and Lagerlof (1997) have argued that rentseeking efforts need not be socially wasteful because they provide valuable information to help the rentgiver decide the winner of the contest (see also Bhagwati, 1982).

${ }_{5}^{5}$ In fact, Konrad (2000) uses the term standard rent-seeking effort for what we refer to here as productive effort.
} 
"Relative comparisons imply that individuals can increase their wealth in two ways. Competition encourages increased effort, which has a positive effect on output. This is the idea of Lazear and Rosen (1981). But competition also discourages cooperation among contestants and can lead to outright sabotage."

In this review, I follow the interpretation in Lazear (1989) and in the majority of papers on sabotage in the sense there is a productive effort and destructive effort in the contest. Obviously, this does not lead to a conflict between standard rent-seeking models and tournament models because sabotage is equivalent to socially wasteful rent-seeking expenditures in the sense of Tullock (1967) and Krueger (1974).

\subsection{Game-theoretic models: why study sabotage in contests?}

Is it useful to model sabotage when it ultimately has the same effect as standard rent-seeking effort? Like standard rent-seeking effort, doesn't sabotage increase a player's probability of success or his payoff? How then can modeling sabotage in a contest lead to any useful insights? Surprisingly, a contest with sabotage leads to insights that cannot be gleaned from a contest without sabotage. For example, sabotage crowds out productive effort and thereby reduces output. It also leads to adverse selection in contests.

Consider a labor tournament (a contest) with no sabotage. In this environment, the standard result is that an increase in the prize (i.e., high-powered incentives) will lead to an increase in effort and therefore aggregate output. In this framework, it is difficult to explain the observation that wage compression among workers can be efficient. However, as Lazear (1989) showed in a contest in which sabotage is possible, wage compression (i.e., a lower-powered incentive because the spread between the wage of the 
winner and the wage of losers is smaller) may increase output because it reduces the workers' efforts in uncooperative or sabotage activities. But as Lazear (1989) also notes, wage compression also decreases productive effort, so the effect on output is not guaranteed. However, in organizations plagued by high levels of destructive behavior, the fall in sabotage as a result of wage compression is likely to be sufficiently big and this will make the policy optimal.

A standard result in rent-seeking contests is that an increase in the number of contestants increases aggregate rent-seeking efforts; the competition effect. But as Konrad (2000) showed, this standard result may no longer hold if there is sabotage. This is because unlike the standard rent-seeking effort, sabotage has a public-good characteristic. When a player in a contest increases his rent-seeking effort, it increases his probability of winning and all the benefits accrue to him alone. In contrast, when a player weakens a specific player by sabotaging him, all other players (including the saboteur) benefit. Konrad (2000) refers to this as the dispersion effect of sabotage. Because of this effect, the benefit per player is smaller the higher is the number of players in the game. Accordingly, players have a greater incentive to invest more effort in sabotage if the total number of players is small. Therefore, it is no longer the case that an increase in the total number of players necessarily leads to an increase in the aggregate sum of efforts.

Chen (2003) and Munster (2007) found that it is the most able contestant who gets sabotaged heavily because he is the biggest threat to the other contestants. ${ }^{6}$ This has a perverse implication for the composition of players in a contest. More able contestants

\footnotetext{
${ }^{6}$ Gürtler et al. $(2010,2012)$ also find that contestants who exert high effort in the first stage of a two-stage contest are sabotaged more than those who exert low effort. Hence there is less incentive to exert the high effort.
} 
may stay out because of the fear of excessive sabotage. If the field is dominated by less able contestants, then this will lead to a result akin to adverse selection wherein the bad drives away the good. There is some anecdotal evidence for this where in some countries, the politics of insults and character assassination implies that politics is dominated by people with poorer outside options.

It turns out that a model in which competition is between teams as opposed to individuals may lead to a result that is in contrast to the aforementioned result in Chen (2003) and Munster (2007). In particular, Gurtler (2008) shows that in contest between teams, each team directs all its sabotage activities at only the opponent's least able members. This is due to the fact that a player's productive contribution to his team's success is subject to diminishing returns. Since the contribution of less able teammates is smaller than the contributions of more able teammates, diminishing returns implies that less able teammates have a higher marginal contribution. Also, given an assumption that the contributions of teammates are complements, it follows that the marginal contribution of a member of a team is increasing in the contribution of other team members and therefore is highest for the least able members. These two effects imply the least able team members are, on the margin, most productive and so that it is most attractive to sabotage them. ${ }^{7}$

Amegashie and Runkel (2007) find that the most able contestant may be the only player who invests in sabotage. Unlike standard models of sabotage, a player in Amegashie and Runkel (2007) cannot sabotage his current opponent but can instead

\footnotetext{
${ }^{7}$ In model of a team production, Bose et al. (2010) and Krakel and Muller (2012) find that it may be optimal for a team member to sabotage the team. These models do not consider contests between teams because there is only one team. They are also not contests among members of a team because the principal cannot reward agents according to their relative performance since individual contributions to team performance are not contractible.
} 
potential or future opponents. Then given that the most able player has the highest valuation of advancing to the next stage of the contest, there is an equilibrium in which he engages in sabotage while the other less able players do not.

In a two-stage contest with sabotage, Amegashie (2012) finds that productive effort is increasing in the prize when the prize is below a certain threshold and then stays constant thereafter. There is no investment in sabotage below this threshold. Beyond this threshold, the players invest in only sabotage effort and it is increasing in the value of the prize. Therefore, the ratio of productive effort to sabotage effort falls as the value of the prize increases beyond a certain threshold. After some point, it is not profitable to increase productive effort even if the value of the prize increases. As in Chen (2003) and Munster (2007), being productive invites too much sabotage but this result is proven in a model with identical contestants. ${ }^{8}$

It is important to note that in Lazear's (1989) framework and other models of sabotage in contests, both productive and sabotage efforts are monotonically increasing in the prize (i.e., the players' valuation). In these models, sabotage only partially crowds out productive effort. The result in Amegashie (2012) implies that beyond a threshold value of the prize, sabotage fully crowds out any additional productive effort that would have been put forth by the players in the absence of sabotage. ${ }^{9}$

\footnotetext{
${ }^{8}$ The model in Amegashie (2012) also yields the result, first discovered by Konrad (2000), that there is no investment in sabotage if the number of contestants is sufficiently high.

${ }^{9}$ In Chen (2003), the equilibrium productive effort is increasing in the value of the prize while sabotage effort is independent of the prize. Hence, there is no additional crowding out of productive effort as the prize increases. Chen (2003), this result is not general and that it is driven by a linearity assumption.
} 


\section{Empirical and experimental studies of sabotage in contests}

Since sabotage is typically an illegal and hidden activity ${ }^{10}$ it does not lend easily itself to empirical tests. This makes it difficult to assess its extent and its victims. To get round his problem, researchers have resorted to experimental methods.

Consistent with Lazear (1989), a number of experimental studies show that sabotage activities increase as the spread between winner and loser prizes widens (Harbring and Irlenbusch, 2005, 2008, 2011; Vandegrift and Yavas, 2010). They also find that the contest-designer responds to this behavior by reducing the spread in the prizes. $^{11}$

In Harbring and Irlenbusch (2005), groups of four agents compete in a rank-order tournament. In one of the treatments, there is a principal who determines winner and loser prizes. In this treatment, subjects play a two-stage game in which the principal offers a wage contract to the four agents in the first stage and then, in the second stage, the four agents choose their effort levels simultaneously in a rank-order tournament. In a benchmark treatment with an exogenous prize structure, the contestants engage in a simultaneous move rank-order tournament. The results of the experiment indicate that both productive effort and sabotage increase in the winner's prize. Furthermore, sabotage is higher when the prize structure is not exogenous but chosen by the principal.

Harbring and Irlenbusch (2011) allow for communication between the contestants and the principal. They find that communication helps curb sabotage because the principal and the agents manage to agree to small prize spreads in exchange for high output. They also find that sabotage is lower when the instructions frame the

\footnotetext{
${ }^{10}$ Not all sabotage is illegal. For example, negative campaigning in elections is not illegal.

${ }^{11}$ This result is also obtained in the experiments of Falk et al. (2008).
} 
experimental tasks as an employer-employee relationship and refer to the action of lowering other participants' effort as "sabotage".

Harbring et al. (2007) compare sabotage behavior in symmetric contests to behavior in asymmetric contests, wherein low-ability players compete with high-ability players. They find that high-ability contestants tend to sabotage each other's effort more than they sabotage low-ability contestants. They also find that revealing the identity of the saboteur leads to less sabotage relative treatments in which the saboteur's identity is hidden. One may think of the revelation of the saboteur's identity as in increase in the social cost of engaging in sabotage.

In Carpenter et al. (2010), agents can influence the performance measurement of their competitors in a real-effort experiment. In particular, agents engage in a clerical task whose output is measured along two dimensions: quantity and quality. Agents privately evaluate each other's performance along these two dimensions. Underreporting both the performance of one's opponent quantity and/or quality is sabotage and is costless in the experiments. It turns out that the anticipation of the harmful influence of competitors discourages agents to exert effort in the first place. Therefore, consistent with the models of Chen (2003), Munster (2007, Gurtler et al (2010, 2012), and Amegashie (2012), sabotage may not only lead to the destruction of output, but, will also discourage agents from exerting productive effort. ${ }^{12}$

Balafoutas et al. (2012) rely on a natural experiment in Judo World Championships to study sabotage in contests. They looked at the effects of a rule change

\footnotetext{
${ }^{12}$ In an experiment on contests for status, Charness et al (2012) find that sabotage opportunities have a strong detrimental effect on performance and that inducing group identity discourages sabotage among peers but increases in-group rivalry.
} 
in 2009 effectively reduced the cost of engaging in sabotage (i.e., breaking an opponent's attack in an unsportsmanlike manner, an act seen as sabotage). Based on a dataset of 1422 fights and consistent with theoretical findings, the authors found (i) a considerable increase in the use of sabotage following the rule change in 2009, (ii) strong evidence that sabotage is more likely to be used by relatively less competent individuals, and to be targeted at more competent individuals, and (iii) that sabotage reduced the welfare of spectators based on a survey administered on 115 spectators of a Judo Grand Prix.

Brown and Chowdhury (2012) examine a contest in which contestants can be handicapped. In particular, they consider horse races where in handicap races, horses within a range of abilities are permitted to take part, but superior horses are given heavier weights. Using data on 9646 U.K. horse-races in 2010, they find that participants in handicap races are substantially more likely to commit sabotage ${ }^{13}$ than those competing in non-handicap races. That is, the leveling the field increases the likelihood of sabotage in contest environments.

Using the increase in points for winning a game from 2 to 3 as a measure of an increase in the prize (value) of winning a game in the Spanish football league, Garicano and Palacios-Huerta (2006) and del Corral et al. (2010) find an increase in sabotage (fouls) as a result of this rule change. ${ }^{14}$

\section{Policies to reduce sabotage}

\footnotetext{
${ }^{13}$ Sabotage takes the form of interference. This may include one horse knocking into another horse, a horse forcing another off their racing line, and a jockey stealing another jockey's whip during the race. According to Brown and Chowdhury (2012), in 2010 there were 2564 instances of alleged sabotage, with 847 leading to a guilty verdict.

${ }^{14}$ Deutscher et al. (2011) undertake a similar exercise using German data.
} 
Since sabotage effort crowds out productive effort and can discourage highly able people from competing in a contest, it is important to think of ways of mitigating it. As noted earlier, in labor tournaments, Lazear (1989) recommends wage compression as an optimal response to the counter-productive behavior of contestants.

Lazear (1989), Lazear (1995), Chen (2003, 2005) recommend external recruitment in labor tournaments because someone who is yet to join an organization is more difficult to sabotage. Lazear (1989, p. 577) and Lazear (1995, chapter 3) document that before the break-up of AT\&T, its president was usually chosen from its subsidiaries as opposed to choosing him/her from the head office. This was because there appeared be more sabotage activities if the competition was among people who were in the head office than among people from different subsidiaries.

A policy in the spirit of the external recruitment is to keep opposing contestants at arm's length. Lazear (1989) suggests that organizations should take the personalities of their workers into account. Some workers are too aggressive (hawks) while others not (doves). He makes the insightful point that in organizations where winning is crucial for promotion, the upper echelons of the organizations will be dominated by hawks. If so, bonuses, based on individual or output, may be better for high-level management because they do induce sabotage compared to payments based on relative performance.

In a two-stage contest where contestants sabotage those who are high performers, Gürtler et al. (2012) show that the disincentive effect of sabotage can be mitigated by concealing information about performance in the first stage. 
Based on their experimental findings, Harbring and Irlenbusch (2011) suggest that organizations should use terms that refer to the immoral character of the sabotage activity in their newsletters or codes of conduct.

\section{Conclusion}

The literature on sabotage in contests is very small and relatively new. I have presented an overview of this literature. Based on both theoretical and empirical studies, the general consensus is that sabotage in contests crowds out productive effort and reduces welfare.

The literature on contests began with models of complete information about the types or abilities of players. In recent years, there have been models of contests with incomplete information. None of these models studies the incentives of players to sabotage each other. This will be a useful direction to move the literature on sabotage in contests. 


\section{Appendix A: A mathematical model of sabotage in contests}

For simplicity, consider a contest with two risk-neutral players, 1 and 2. Suppose that player $\mathrm{j}$ can choose productive effort, $\mathrm{e}_{\mathrm{j}}$, and sabotage effort, $\mathrm{s}_{\mathrm{j}}, \mathrm{j}=1,2$. Let the total cost of effort for each player be $\mathrm{C}\left(\mathrm{e}_{\mathrm{j}}+\mathrm{s}_{\mathrm{j}}\right)$, which is an increasing and strictly convex function and $\mathrm{C}(0)=0$. Suppose that the players have same valuation, $\mathrm{V}>0$, of the prize. In a labor tournament, the player's valuation is equal to the difference between the winner's wage and loser's wage.

Let player j's output be $\mathrm{q}_{j}=\mathrm{e}_{\mathrm{j}}-\mathrm{s}_{\mathrm{k}}+\varepsilon_{\mathrm{j}}$, where $\varepsilon_{\mathrm{j}}$ is a continuous random variable and $\mathrm{k} \neq \mathrm{j}, \mathrm{j}=1,2 ; \mathrm{k}=1,2$. Assume that $\varepsilon_{1}$ and $\varepsilon_{2}$ are identically and independently distributed with a known density. These random variables are intended to capture luck, noise, or measurement error in output.

The player with the higher output wins the contest. Note that player j's output is increasing in his productive effort but decreasing in his opponent's sabotage effort.

Player j's payoff function is

$\Omega_{\mathrm{j}}=\operatorname{prob}\left(\mathrm{q}_{\mathrm{j}}>\mathrm{q}_{\mathrm{k}}\right) \mathrm{V}-\mathrm{C}\left(\mathrm{e}_{\mathrm{j}}+\mathrm{s}_{\mathrm{j}}\right)$,

$\mathrm{k} \neq \mathrm{j}, \mathrm{j}=1,2 ; \mathrm{k}=1,2$

The payoff in (1) can be written as:

$\Omega_{j}=F\left[\left(e_{j}-s_{k}\right)-\left(e_{k}-s_{j}\right)\right] V-C\left(e_{j}+s_{j}\right)$,

where $F(\cdot)$ is the cumulative distribution function of $\varepsilon_{k}-\varepsilon_{j}$. Given $F^{\prime}(\cdot)=f(\cdot)>0$, it follows that player $j$ 's probability of success, $P_{j}=F\left[\left(e_{j}-s_{k}\right)-\left(e_{k}-s_{j}\right)\right]$, is increasing in his productive effort and sabotage effort but decreasing in his opponent's productive 
effort and sabotage effort. ${ }^{15}$ Player $\mathrm{j}$ chooses his productive and sabotage efforts to maximize the payoff function in (2).

The above approach to modeling contests was pioneered by Lazear and Rosen (1981) in a model without sabotage. It was the approach used by Lazear (1989), Chen (2003), Munster (2007) and other papers discussed in this review to model sabotage in contests. An equivalent but reduced-form approach is to define player j's success probability as:

$$
P_{j}=\frac{g\left(e_{j}-s_{k}\right)}{g\left(e_{j}-s_{k}\right)+g\left(e_{k}-s_{j}\right)},
$$

where $g^{\prime}(\cdot)>0$. One may argue that this assumes that there exists a distribution function for which (3) holds. ${ }^{16}$ The reduced-form function in (3) is called the contest success function. ${ }^{17}$ In a model without sabotage, this approach was pioneered by Tullock (1980) in his study of rent-seeking and it is the approach used by Konrad (2000), Amegashie and Runkel (2007), and Amegashie (2012). ${ }^{18}$

The first order conditions for player j's problem are:

$$
\frac{\partial \Omega_{\mathrm{j}}}{\partial \mathrm{e}_{\mathrm{j}}} \leq 0, \mathrm{e}_{\mathrm{j}} \geq 0, \mathrm{e}_{\mathrm{j}} \frac{\partial \Omega_{\mathrm{j}}}{\partial \mathrm{e}_{\mathrm{j}}}=0
$$

and

\footnotetext{
${ }^{15}$ Note, for example, that if $\varepsilon_{\mathrm{k}}$ and $\varepsilon_{\mathrm{j}}$ are each normally distributed with a given mean and variance, then the convolution $\mathrm{f}\left(\varepsilon_{\mathrm{k}}-\varepsilon_{\mathrm{j}}\right)$ will also be a normal distribution with a given mean and variance.

${ }^{16}$ The function in (3) can be derived by assuming that the output takes the multiplicative form, $\mathrm{q}_{\mathrm{j}}=\left(\mathrm{e}_{\mathrm{j}}-\mathrm{s}_{\mathrm{k}}\right) \varepsilon_{\mathrm{j}}$ and $\varepsilon_{\mathrm{k}}$ and $\varepsilon_{\mathrm{j}}$ have an exponential distribution. For a review of the micro-foundations of this approach, see Jia, Skaperdas, and Vaidya (2011).

${ }^{17}$ Another reduced-form function used is the difference-form contest success function, $\mathrm{F}\left[\left(\mathrm{e}_{\mathrm{j}}-\mathrm{s}_{\mathrm{k}}\right)-\left(\mathrm{e}_{\mathrm{k}}-\mathrm{s}_{\mathrm{j}}\right)\right]=\left(\mathrm{e}_{\mathrm{j}}-\mathrm{s}_{\mathrm{k}}\right)-\left(\mathrm{e}_{\mathrm{k}}-\mathrm{s}_{\mathrm{j}}\right)$; see Che and Gale $(2000)$.

${ }^{18}$ However, in Amegashie (2012), productive effort directly enters the contest success function (CSF) while destructive effort does not. Instead, destructive effort directly increases one's opponent's marginal cost of productive effort and hence indirectly reduces the opponent's success probability.
} 


$$
\begin{aligned}
& \frac{\partial \Omega_{j}}{\partial s_{j}} \leq 0, s_{j} \geq 0, s_{j} \frac{\partial \Omega_{j}}{\partial s_{j}}=0 . \\
& j=1,2 .
\end{aligned}
$$

A pure-strategy Nash equilibrium must satisfy equations (4) and (5) for both players and second-order conditions must be satisfied as well. Consider an interior solution for both productive effort and sabotage effort: $e_{j}>0$ and $s_{j}>0, j=1,2$. This gives

$$
\frac{\partial \Omega_{j}}{\partial e_{j}}=f\left[\left(e_{j}-s_{k}\right)-\left(e_{k}-s_{j}\right)\right] V-C^{\prime}\left(e_{j}+s_{j}\right)=0
$$

and

$$
\frac{\partial \Omega_{j}}{\partial s_{j}}=f\left[\left(e_{j}-s_{k}\right)-\left(e_{k}-s_{j}\right)\right] V-C^{\prime}\left(e_{j}+s_{j}\right)=0
$$

$\mathrm{j}=1,2$. Assume that second-order conditions hold.

In a symmetric equilibrium, equations (6) and (7) become

$$
f(0) V-C^{\prime}(\hat{e}+\hat{s})=0
$$

and

$$
f(0) V-C^{\prime}(\hat{e}+\hat{s})=0
$$

Equations (6a) and (7a) are the same. Therefore, we cannot determine unique values for the individuals efforts, $\hat{\mathrm{e}}$ and $\hat{\mathrm{s}}$. But the aggregate effort, $\hat{\mathrm{e}}+\hat{\mathrm{s}}$, is unique.

When sabotage is not possible, the optimal productive effort, $\mathrm{e}^{*}>0$, in a symmetric equilibrium satisfies

$$
\mathrm{f}(0) \mathrm{V}-\mathrm{C}^{\prime}\left(\mathrm{e}^{*}\right)=0
$$

Then comparing (8) to (6a) or (7a) and rearranging gives 
$\mathrm{e}^{*}=\hat{\mathrm{e}}+\hat{\mathrm{s}}$.

Total effort remains the same as in Chen (2003). Given $\hat{\mathrm{s}}>0$, equation (9) implies that $\hat{\mathrm{e}}<\mathrm{e}^{*}$. Productive effort is smaller if sabotage is positive. Therefore, sabotage crowds out productive effort.

\section{References}

Amegashie, J.A. 2012. Productive versus destructive efforts in contests. European Journal of Political Economy 28, 461-468.

Amegashie, J.A., Runkel, M., 2007. Sabotaging potential rivals. Social Choice and Welfare 28, 143-162.

Austin-Smith, D., and Wright, J.R. 1992. Competitive lobbying for legislators' votes. Social Choice and Welfare 9: 229-257.

Balafoutas, L., Lindner, F., and Sutter, M. 2012. Sabotage in tournaments: evidence from a natural experiment. Kyklos 65: 425-441.

Bhagwati, J.N., 1982. Directly unproductive profit-seeking (DUP) activities. Journal of Political Economy 90: 988-1002.

Bose, A., Pal, D., and Sappington, D.E.M., 2010. Equal pay for unequal work: limiting sabotage in teams. Journal of Economics and Management Strategy 19: 25-53.

Carpenter, J., Matthews, P.H., Schirm, J., 2010. Tournaments and office politics: evidence from real effort experiment. American Economic Review 100, 504-517.

Charness, G., Masclet, D., and Villeval, M.C. 2012. The dark side of competition for status. Working Paper, University of California, Santa Barbara.

Che, Y-K., and Gale, I. (2000). Difference-form contests and the robustness of all-pay auctions. Games and Economic Behavior 30: 22-43.

Chen, K.-P., 2003. Sabotage in promotion tournaments. Journal of Law, Economics and Organisation 19, 119-140.

Chen, K.-P., 2005. External recruitment as an incentive device. Journal of Labor Economics 23: 259-277.

Chowdhury, S.M., and Brown, A. 2012. Sabotage in handicap contests. University of East Anglia, mimeo. 
Congleton, R.D., Hillman, A.L., Konrad, K.A. (Eds.), 2008a. 40 Years of Research on Rent Seeking 1: Theory of Rent Seeking. Springer, Heidelberg.

Congleton, R.D., Hillman, A.L., Konrad, K.A. (Eds.), 2008b. 40 Years of Research on Rent Seeking 2 - Applications: Rent Seeking in Practice. Springer, Heidelberg.

del Corral, J., Prieto-Rodrigeuz, J., Simmons, R., 2010. The effect of incentives on sabotage: the case of Spanish football. Journal of Sports Economics 11: 243-260.

Deutscher, C., Frick, B., Gurtler, O., Prinz, J., 2011. Sabotage in tournaments with heterogeneous contestants: a field study. University of Paderborn, mimeo.

Drago, R., and Garvey, G.T., 1998. Incentives for helping on the job: theory and evidence. Journal of Labor Economics 16: 1-25.

Falk, A. Fehr, E. and Huffman, D. 2008. The power and limits of tournament incentives. Working Paper, University of Bonn.

Garicano, L., Palacios-Huerta, I., 2006. Sabotage in tournaments: making the beautiful game a bit less beautiful. University of Chicago/Brown University mimeo.

Gürtler, O. 2008. On sabotage in collective tournaments. Journal of Mathematical Economics 44: 383-393.

Gürtler, O.,and Münster, J., 2010. Sabotage in dynamic tournaments. Journal of Mathematical Economics. 46: 179-190.

Gürtler, O., Münster, J. and Nieken, P. (2012). Information policy in tournaments with sabotage. Scandinavian Journal of Economics, forthcoming.

Harbring, C., and Irlenbusch, B. 2005. Incentives in tournaments with endogenous prize selection. Journal of Institutional and Theoretical Economics 127: 636-663.

Harbring, C., and Irlenbusch, B. 2008. How many winners are good to have? On tournaments with sabotage. Journal of Economic Behavior and Organization 65: 682702.

Harbring, C., and Irlenbusch, B., 2011. Sabotage in tournaments: evidence from a laboratory experiment. Management Science 57, 611-627.

Harbring, C., Irlenbusch, B., Krakel, M., Selten, R., 2007. Sabotage in corporate contests - experimental analysis. International Journal of the Economics of Business 14: 367392. 
Jia, H., Skaperdas, S., and Vaidya, S. 2011. Contest functions: theoretical foundations and issues in estimation. International Journal of Industrial Organization, forthcoming. Konrad, K.A., 2000. Sabotage in rent-seeking contests. Journal of Law, Economics and Organisation 16, 155-165.

Krakel, M., and Muller, M. 2012. Sabotage in teams. Economics Letters 115: 289-292.

Krueger, A. 1974. The political economy of the rent-seeking society. American Economic Review 64: 291-303.

Lagerlof, J. 1997. Lobbying, information, and private and social welfare. European Journal of Political Economy 13: 615-637.

Lazear, E., 1989. Pay equality and industrial politics. Journal of Political Economy 97, 561-580.

Lazear, E., 1995. Personnel Economics. MIT Press, Cambridge.

Lazear, E., and Rosen, S. 1981. Rank-order tournaments as optimal labor contracts. Journal of Political Economy 89: 841-864.

Lohmann, S., 1995. Information, access, and contributions: a signaling model of lobbying. Public Choice 85: 267-284.

Münster, J., 2007. Selection tournaments, sabotage, and participation. Journal of Economics and Management Strategy 16, 943-970.

Tullock, G. 1967. The welfare economics of tariffs, monopolies, and theft. Western Economic Journal 5: 224-232.

Tullock, G. 1980. Efficient rent seeking. In J. M. Buchanan (Ed.), Toward a theory of therent-seeking society (pp. 269-282), A\&M University Press, College Station: Texas.

Vandegrift, D., Yavas, A. and Brown, P. 2007. Incentive effects and overcrowding in tournaments: an experimental analysis. Experimental Economics 10: 345-368. 